\title{
Peertechz
}

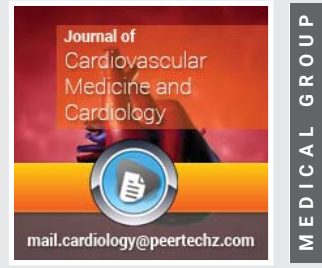

\section{Extreme Stent Malapposition after Percutaneous Coronary Intervention in Bifurcation Lesions: An Optical Coherence Tomography}

\author{
Hesham Refaat ${ }^{1,2 *}$ \\ ${ }^{1}$ Department of Cardiology, Zagazig University, Zagazig, Egypt \\ ${ }^{2}$ Department of Interventional Cardiology, San Giovanni Hospital \& Centro per la Lotta Contro I'Infarto, \\ CLI Foundation, Rome, Italy
}

Received: 30 November, 2020

Accepted: 09 December, 2020

Published: 10 December, 2020

*Corresponding author: Hesham Refaat, MD, Department of Cardiology, Zagazig University, Zagazig, Egypt, Tel: +201001929933; Email: heshamrefat22@yahoo. com, hrefaat400@gmail.com

Keywords: Optical coherence tomography; Bifurcation lesion; Extreme malapposition

https://www.peertechz.com

Check for updates

\section{Abstract \\ Background: Anecdotal cases of bifurcation lesion stenting indicated that a wrong kissing Balloon Inflation (KBI) technique can lead to extreme stent malapposition with even stent crushing. The aim of this study was to quantify the occurrence of this finding, despite achieving acceptable angiographic results. \\ Methods: A total of 229 bifurcation lesions were included in this study. Optical Coherence Tomography (OCT) was obtained immediately after KBI. The stented bifurcation lesions were classified into 2 groups: group 1 with extreme malapposition (malapposition distance $\geq 1 \mathrm{~mm}$ and in-stent minimal Cross Sectional Area (CSA) $<70 \%$ of the distal reference CSA), and group 2 (malapposition distance $<1 \mathrm{~mm}$ and/or in-stent CSA $>70 \%$ of the distal reference CSA). \\ Results: OCT revealed a mean stent malapposition distance of $0.43 \pm 0.47 \mathrm{~mm}$ extending for a mean length of $1.88 \pm 1.82 \mathrm{~mm}$. Forty four cases (19.2\%) of extreme stent malapposition were observed, and characterized by a stent malapposition distance of $1.49 \pm 0.3 \mathrm{~mm}$. These stents were under-expanded with lower stent eccentricity index (SEI), compared with those without extreme malapposition (48.38 \pm 9.67 vs. $60.97 \pm 33.29, p=0.46$ and $0.57 \pm 0.15$ vs. $0.74 \pm 0.89$, $p<0.001$, respectively). This is mainly attributed to the wrong passage of guide-wires, while performing wire exchange during $\mathrm{KBI}$ technique.}

Conclusion: The bifurcation stenting requiring a KBI technique can be complicated by an extreme degree of stent malapposition; or even stent crushing in some cases, caused by the wrong passage of one or both guide-wires through the stents, during the wire exchange.

\section{Introduction}

Bifurcation lesions of the coronary tree are common findings that occur in $15-20 \%$ of Percutaneous Coronary Interventions (PCI) [1]. Treatment of these bifurcation lesions is a challenge for interventional cardiologists and often requires, in some cases, the Kissing Balloon Inflation (KBI) technique to guarantee the optimal expansion of the stent and the opening of jailed side branch vessel take-off [2].

Optical Coherence Tomography (OCT) provides detailed information after stent positioning, showing features such as edge dissection, tissue protrusion and struts malapposition.
It is rather common for OCT to visualize these unfavourable findings despite the achievement of an optimal result at coronary angiography [3].

Anecdotal cases of left main stenting performed with final KBI technique and imaged with OCT at the end of procedure revealed that an improper $\mathrm{KBI}$ technique can lead to marked malapposition of the stent struts, due to the stent crushing against vessel wall [4].

The aim of this study was to document and quantify the occurrence of this extreme degree of malapposition in bifurcation lesions treated with provisional strategy followed by KBI technique. 


\section{Methods}

\section{Study population and design}

From January 2018 to June 2020, a total of 236 consecutive patients admitted to our institution who underwent stent implantation across bifurcation lesions followed by KBI with final OCT assessment were primarily enrolled in this study. The inclusion criteria were: (i) de novo bifurcation lesions with Side Branch (SB) diameter $\geq 2.5 \mathrm{~mm}$ based on visual estimation; (ii) SB opening with KBI due to suboptimal angiographic results and compromised ante-grade flow after main branch (MB) stenting; and (iii) OCT assessment after MB stenting and final KBI. Insufficient quality of the OCT pullback, due to incomplete blood removal, led to exclusion of 7 patients from this study [5]. Thus, 229 patients were finally included in this study. Ethical approval was waived in the light of the observational retrospective design. Finally, all patients provided written informed consent for the index procedure and for the use of their clinical data

\section{Coronary angiography protocol and procedural details}

Coronary angiography was performed via the transradial or transfemoral approach using 6 or 7 Fr sheaths and catheters with administration of $0.2 \mathrm{mg}$ intracoronary nitroglycerin. Bifurcation lesions were addressed with quantitative coronary angiography (QCA) using two orthogonal views and were classified according to the Medina classification, depending on the presence or absence of $>50 \%$ stenosis in the proximal and distal MB as well as the SB ostium [6].

The provisional strategy was the preferred approach; however, in some cases a more complex strategy was applied. The choice to use a simple or complex technique was at the operator's discretion. After re-wiring of the SB, KBI was performed with two balloons that were sized based on the SB and $\mathrm{MB}$ diameters distal to the bifurcation. In some cases, due to a suboptimal result of the SB (abrupt closure, flow-limiting dissection, $>75 \%$ stenosis, TIMI flow $<3$ ), a second stent was deployed in the SB [7].

Procedural success was defined as a final diameter stenosis $<30 \%$ in the $\mathrm{MB}$ and $<50 \%$ in the $\mathrm{SB}$ by visual assessment with TIMI 3 flow in both the MB and SB [8]. OCT was performed immediately after stent implantation and KBI inflation. After stent implantation, all patients received dual anti-platelet therapy.

\section{OCT images acquisition and analysis}

OCT imaging was performed in all cases immediately after KBI inflation using a commercially available frequency domain (C7 System; LightLab Imaging Inc/ St Jude Medical, Westford, MA) OCT system (FD-OCT) connected to $2.7 \mathrm{~F}$ OCT imaging catheter (C7 Dragonfly; LightLab Imaging Inc/ St Jude Medical, Westford, MA) which was advanced distally in the target main vessel $[9,10]$.

The OCT data were analyzed by an expert operator, blinded to the angiographic and clinical findings, using previously validated criteria for OCT stent assessment [11-14]. The stented cases were divided into two groups; group (1) with extreme malapposition having a malapposition distance $\geq 1 \mathrm{~mm}$ and in-stent minimal Cross Sectional Area (CSA) $<70 \%$ of distal reference CSA, and group (2) with malapposition distance < $1 \mathrm{~mm}$ and/or in-stent CSA $>70 \%$ of distal reference CSA [15].

In particular, reference lumen area (RLA), stent expansion, intrastent minimum lumen area (MLA), minimum stent diameter, stent eccentricity index (SEI), and stent struts malapposition were assessed $[10,15]$.

\section{Statistical analysis}

Data distribution was assessed according to the Kolgormonov-Smirnov test. For analysis of patient characteristics, categorical data were compared using the chi-square test or Fisher exact test, depending on which test was most suitable; these data are presented as frequencies (percent). Continuous variables were compared using an unpaired Student's t-test or Mann-Whitney U-test, as appropriate, and data were expressed as mean \pm standard deviation. All tests were two-sided, and a p-value of $<0.05$ represented statistically significant differences. All analyses were performed using SPSS version 20 (SPSS Inc., USA).

\section{Results}

\section{Baseline clinical and angiographic characteristics}

A total of 229 patients (age $66.4 \pm 15.3$, male sex 140 patients, $61.1 \%$ ) with de novo bifurcation lesions entered the study. Demographic and clinical characteristics are depicted in (Table 1). There were no complications related to the OCT procedure. Ninety patients $(39.3 \%)$ had stable angina pectoris (SAP), while the remaining 139 patients presented with ACS; 95 with non ST elevation ACS (41.5\%) and 40 with ST elevation ACS (19.2\%). Bifurcation lesion involving the left main coronary

Table 1: Demographic and clinical characteristics.

\begin{tabular}{|c|c|}
\hline Variables & $\begin{array}{c}\text { All patients } \\
\quad(n=229)\end{array}$ \\
\hline Age, y & $66.4 \pm 15.3$ \\
\hline Male sex, n (\%) & $140(61.1 \%)$ \\
\hline \multicolumn{2}{|c|}{ Cardiovascular risk factors, n (\%) } \\
\hline Hypertension & $148(64.6 \%)$ \\
\hline Diabetes mellitus & $163(71.2 \%)$ \\
\hline Dyslipidemia & $157(68.6 \%)$ \\
\hline Current smoker & $121(52.8 \%)$ \\
\hline Family history of CHD & $76(33.2 \%)$ \\
\hline Previous MI & $39(17.5 \%)$ \\
\hline \multicolumn{2}{|l|}{ Clinical Presentation, n (\%) } \\
\hline SAP & $90(39.3 \%)$ \\
\hline NSTE-ACS & $95(41.5 \%)$ \\
\hline STE-ACS & $44(19.2 \%)$ \\
\hline $\begin{array}{l}\text { Legend: CHD: Coronary Heart Disease; M } \\
\text { ST Elevation Acute Coronary Syndromes; } \\
\text { ST-Elevation Acute Coronary Syndromes }\end{array}$ & $\begin{array}{l}\text {; NSTE-ACS: } \\
\text { ctoris; STE-AC }\end{array}$ \\
\hline
\end{tabular}


artery (LMCA) were noticed in 101 patients $(44.1 \%)$, while in the remaining 128 patients $(55.9 \%)$ the bifurcation lesion involved the left anterior descending coronary artery (LAD). These bifurcation lesions were classified angiographically according to Medina classification (Table 2). Most cases showed B2 lesion according to ACC/AHA classification (68.6\%).

\section{Procedural characteristics}

Provisional strategy without adjunctive stenting was successfully performed in 198 bifurcation lesions (86.5\%). In the remaining 31 lesions (13.5\%) a two stents strategy was adopted due to suboptimal angiographic results. Eight cases were treated with $\mathrm{T}$ stenting, 14 with culotte, and 9 with $\mathrm{T}$ stenting and small protrusion (TAP) techniques. Additional stents were placed in 36 cases $(15.7 \%)$ due to a dissection or a residual significant stenosis at the edges of the implanted stent.

Regarding the type of implanted stents, all lesions were treated with Drug Eluting Stents (DES), 113 with Zotarolimus Eluting Stent (ZES), 56 with Sirolimus Eluting Stent (SES),

Table 2: Angiographic characteristics and QCA data.

\begin{tabular}{|c|c|}
\hline Variables & $\begin{array}{l}\text { All patients } \\
\quad(n=229)\end{array}$ \\
\hline \multicolumn{2}{|c|}{ Angiographic characteristics } \\
\hline \multicolumn{2}{|l|}{ Site of bifurcation lesion } \\
\hline LMCA & $101(44.1 \%)$ \\
\hline LAD & $128(55.9 \%)$ \\
\hline \multicolumn{2}{|l|}{ Medina classification } \\
\hline$(1,1,1)$ & $9(3.9 \%)$ \\
\hline$(1,0,1)$ & $9(3.9 \%)$ \\
\hline$(0,1,1)$ & $14(6.1 \%)$ \\
\hline$(1,1,0)$ & $54(23.6 \%)$ \\
\hline$(1,0,0)$ & $41(17.9 \%)$ \\
\hline$(0,1,0)$ & $94(41.1 \%)$ \\
\hline$(0,0,1)$ & $8(3.5 \%)$ \\
\hline \multicolumn{2}{|c|}{ ACC/AHA classification, n (\%) } \\
\hline Ellis B2 & $157(68.6 \%)$ \\
\hline Ellis C & $72(31.4 \%)$ \\
\hline Calcific lesion, n (\%) & $45(19.7 \%)$ \\
\hline \multicolumn{2}{|l|}{ QCA data } \\
\hline \multicolumn{2}{|l|}{ Before PCI } \\
\hline $\mathrm{RVD}(\mathrm{mm})$ & $3.12 \pm 0.48$ \\
\hline $\operatorname{MLD}(\mathrm{mm})$ & $1.45 \pm 0.68$ \\
\hline$\%$ DS & $65.61 \pm 17.07$ \\
\hline \multicolumn{2}{|l|}{ After PCl } \\
\hline $\mathrm{RVD}(\mathrm{mm})$ & $3.29 \pm 0.46$ \\
\hline $\operatorname{MLD}(\mathrm{mm})$ & $2.93 \pm 0.48$ \\
\hline$\%$ DS & $11.00 \pm 4.24$ \\
\hline \multicolumn{2}{|c|}{$\begin{array}{l}\text { Legend: \% DS: \% Diameter Stenosis; LAD: Left Anterior Desending Coronary } \\
\text { Artery; LMCA: Left Main Coronary Artery; MLD: Minimum Lumen Diameter; PCI: } \\
\text { Percutaneous Coronary Intervention; QCA: Quantitative Coronary Angiography; RVD: } \\
\text { Reference Vessel Diameter }\end{array}$} \\
\hline
\end{tabular}

46 with Everolimus Eluting Stent (EES), and 14 with Biolimus Eluting Stent (BES).The angiographic findings and procedural characteristics are summarized in (Tables 2,3).

\section{OCT findings}

Overall OCT findings are summarized in (Table 4). OCT revealed a mean stent malapposition distance of $0.43 \pm 0.47 \mathrm{~mm}$ extending for a mean length of $1.88 \pm 1.82 \mathrm{~mm}$. Of interest, 44 cases $(19.2 \%)$ of extreme stent malapposition were observed, and characterized by a mean stent malapposition distance of $1.49 \pm 0.3 \mathrm{~mm}$. These stents were under-expanded compared to stents without extreme malapposition (48.38 \pm 9.67 vs. 60.97 $\pm 33.29, \mathrm{p}=0.046)$.

\section{Examples of cases with extreme stent malapposition}

In all cases, OCT imaging was obtained after wire exchange for $\mathrm{KBI}$.

\section{Case \# 1}

The bifurcation lesion involved the LAD and first diagonal branch (D1). OCT showed a severely underexpanded stent (40.43\%) with marked stent malapposition distance $(1.9 \mathrm{~mm})$ extending for a length of $2.8 \mathrm{~mm}$ proximal to D1 takeoff (Figure 1). Wire exchange was done improperly and the wires entered the stent through a side cell instead of entering from the proximal inflow. This resulted in asymmetrical stent expansion ( $\mathrm{SEI}=0.48)$ and extreme malapposition of the proximal stent segment within the LAD.

\section{Case \# 2}

The bifurcation lesions were located in the LMCA. OCT revealed severe malapposition $(1.31 \mathrm{~mm})$ extending for (1.6 $\mathrm{mm}$ ) proximal to SB take-off. While performing re-wiring preceding $\mathrm{KBI}$, one guide-wire entered the main vessel through the main stent inflow. The other wire entered the SB ostium through the gap between the stent and vessel wall (stent malapposition) located in the proximal segment of the stented LMCA. This resulted in severe stent underexpansion (47.65\%) with subsequent extreme malapposition of the stent in the LMCA.

\section{Case \# 3}

The mechanism is the same as in case \# 2, but the bifurcation lesion involved LAD and D1. After guide wire exchange, the wire in the D1 entered the side branch through malapposition gap. This was mainly attributed to the wrong passage of one guidewire outside the proximal end of LAD stent while performing re-wiring. This resulted in marked underexpansion of LAD stent $(57.47 \%)$ due to extreme malapposition of its proximal portion (malapposition distance of $1.23 \mathrm{~mm}$ ).

\section{Case \# 4}

The bifurcation lesion was located in the LMCA. OCT was performed after wire exchange and showed extreme stent malapposition $(1.51 \mathrm{~mm})$ involving the proximal segment 
of the stent in the LMCA for a distance of $1.8 \mathrm{~mm}$. After wire exchange, the guide wire in the main LAD vessel was correctly positioned; however, the SB guide-wire described a wrong path. It first entered the stent through its inflow but went out the stent lumen before reaching the SB take-off, running outside the LMCA stent for a distance of $1.2 \mathrm{~mm}$. The stent had a marked underexpansion $(62.18 \%)$ with maximum malapposition distance of $1.5 \mathrm{~mm}$.

Table 3: Procedural characteristics.

\begin{tabular}{|c|c|}
\hline Variables & $\begin{array}{c}\text { All patients } \\
(n=229)\end{array}$ \\
\hline \multicolumn{2}{|l|}{ Bifurcation PCl strategy, n (\%) } \\
\hline PS & $198(86.5 \%)$ \\
\hline T stenting & $8(3.5 \%)$ \\
\hline Culotte & $14(6.1 \%)$ \\
\hline TAP & $9(3.9 \%)$ \\
\hline Direct stenting, n (\%) & $22(9.6 \%)$ \\
\hline No. of stent implanted & $1.27( \pm 0.45)$ \\
\hline Overlap, n (\%) & $36(15.7 \%)$ \\
\hline DES, n (\%) & $229(100 \%)$ \\
\hline ZES & $113(49.4 \%)$ \\
\hline SES & $56(24.6 \%)$ \\
\hline EES & $46(20.1 \%)$ \\
\hline BES & $14(5.9 \%)$ \\
\hline Mean stent diameter, $\mathrm{mm}$ & $3.03( \pm 0.4)$ \\
\hline Total stent length, $\mathrm{mm}$ & $22.96( \pm 10.25)$ \\
\hline Deployment pressure, atm & $15.3( \pm 2.9)$ \\
\hline No. of balloon inflated & $1.31( \pm 0.47)$ \\
\hline Mean balloon diameter, mm & $2.65( \pm 0.32)$ \\
\hline Total balloon length, $\mathrm{mm}$ & $10.85( \pm 2.08)$ \\
\hline Balloon Inflation pressure, atm & $15.38( \pm 2.22)$ \\
\hline
\end{tabular}

Legend: BES: Biolimus-Eluting Stent; DES: Drug Eluting Stent; EES: EverolimusEluting Stent; PCI: Percutaneous Coronary Intervention; PS: Provisional Strategy; SES: Sirolimus-Eluting Stent; TAP: T stenting and small protrusion; ZES: Zotarolimus-Eluting Stent

\section{Table 4: OCT findings.}

\begin{tabular}{|c|c|c|c|c|}
\hline Variables & $\begin{array}{l}\text { All patients } \\
\qquad(n=229)\end{array}$ & $\begin{array}{l}\text { Stent with } \\
\text { extreme stent } \\
\text { malapposition } \\
\quad(n=44)\end{array}$ & $\begin{array}{l}\text { Stent without extreme } \\
\text { stent malapposition } \\
\qquad(\mathrm{n}=185)\end{array}$ & $P$ value \\
\hline $\mathrm{RLA}, \mathrm{mm}^{2}$ & $9.68 \pm 4.21$ & $10.71 \pm 3.75$ & $9.56 \pm 4.3$ & 0.61 \\
\hline $\begin{array}{c}\text { \% Stent } \\
\text { expansion }\end{array}$ & $59.64 \pm 31.81$ & $48.38 \pm 9.67$ & $60.97 \pm 33.29$ & 0.46 \\
\hline $\begin{array}{c}\text { Intrastent MLA, } \\
\mathrm{mm}^{2}\end{array}$ & $6.05 \pm 1.91$ & $5.04 \pm 1.39$ & $6.15 \pm 1.94$ & 0.27 \\
\hline $\begin{array}{l}\text { Malapposition } \\
\text { distance, mm }\end{array}$ & $0.43 \pm 0.47$ & $1.49 \pm 0.3$ & $0.34 \pm 0.35$ & $<0.001$ \\
\hline $\begin{array}{l}\text { Malapposition } \\
\text { length, mm }\end{array}$ & $1.88 \pm 1.82$ & $2.2 \pm 0.59$ & $1.86 \pm 1.89$ & 0.42 \\
\hline $\begin{array}{l}\text { Minimum stent } \\
\text { diameter, mm }\end{array}$ & $2.41 \pm 0.49$ & $2.06 \pm 0.57$ & $2.45 \pm 0.48$ & 0.14 \\
\hline SEI & $0.73 \pm 0.11$ & $0.57 \pm 0.15$ & $0.74 \pm 0.89$ & 0.001 \\
\hline
\end{tabular}

Legend: MLA: Minimal Lumen Area; OCT: Optical Coherence Tomography; RLA: Reference Lumen Area; SEI: Stent Eccentricity Index

\section{Discussion}

The main findings of this study are summarized as follows: 1) coronary intervention for the treatment of bifurcation lesions requiring a KBI technique, can be complicated by an extreme degree of stent malapposition proximal to SB take off, despite the achievement of an optimal angiographic results; and 2) extreme stent malapposition is due to the wrong passage of one or both guide-wires through the stents, during the wire exchange before KBI technique.

To our knowledge this is the first series of cases of bifurcation lesion where PCI carried on with final OCT assessment, with the goal to address the occurrence of extreme stent malapposition. The incidence of this finding after KBI was higher than expected, being found in $19.2 \%$ of cases, characterized by a high maximum malapposition distance (1.49 $\pm 0.3 \mathrm{~mm})$ and stent underexpansion $(48.38 \pm 9.67 \%)$ at OCT analysis.

The role of malapposition is controversial in the literature, with the majority of studies denying any clinical role for this feature that can be detected with IVUS and OCT $[16,17]$. Ozaki, et al. found a relationship between struts malappostion observed in bifurcations lesions, and the higher risk of stent thrombosis [18]. In presence of extreme degree of stent malapposition after $\mathrm{KBI}$, there are other variables potentially capable of causing stent thrombosis: the increased turbulent coronary flow caused by a large asymmetrical stent expansion, the heterogenicity of drug-elution and the presence of strut uncoverage likely affect the acute and long term follow-up of complex stenting procedures $[10,19]$.

In the vast majority of cases, malapposition is due to under-sizing or incomplete expansion of the stent that does not adhere to the vessel wall [20]. In this study, the reported cases of extreme stent malapposition differ from simple malapposition for the high degree of stent malapposition and its inherent mechanism. In-fact extreme malapposition is due to the stent compression caused by a poorly conducted balloon dilatation. A wrong balloon location (outside the stent struts) pushes the stent against the outer wall, leading to an extreme stent malapposition.

The clinical consequence of extreme stent malapposition is still unclear. In the present study, it was reported that one patient, selected from a series of cases on sub-acute stent occlusion, experienced an acute myocardial infarction 8 days after the coronary intervention. OCT revealed the possible underlying scenario which was attributed to an extreme malapposition of the proximal segment of a stent applied in LMCA with the adoption of the KBI technique [21] (Figure 1).

This new observation elucidates the clinical importance of OCT during the treatment of coronary bifurcations. Based on the present study, the use of OCT should be encouraged to guide coronary intervention to avoid extreme stent malapposition, or even stent crushing after KBI during bifurcation PCI, which is a relatively common finding. The use of OCT before KBI permits to verify whether the imaging-wires have described a correct 


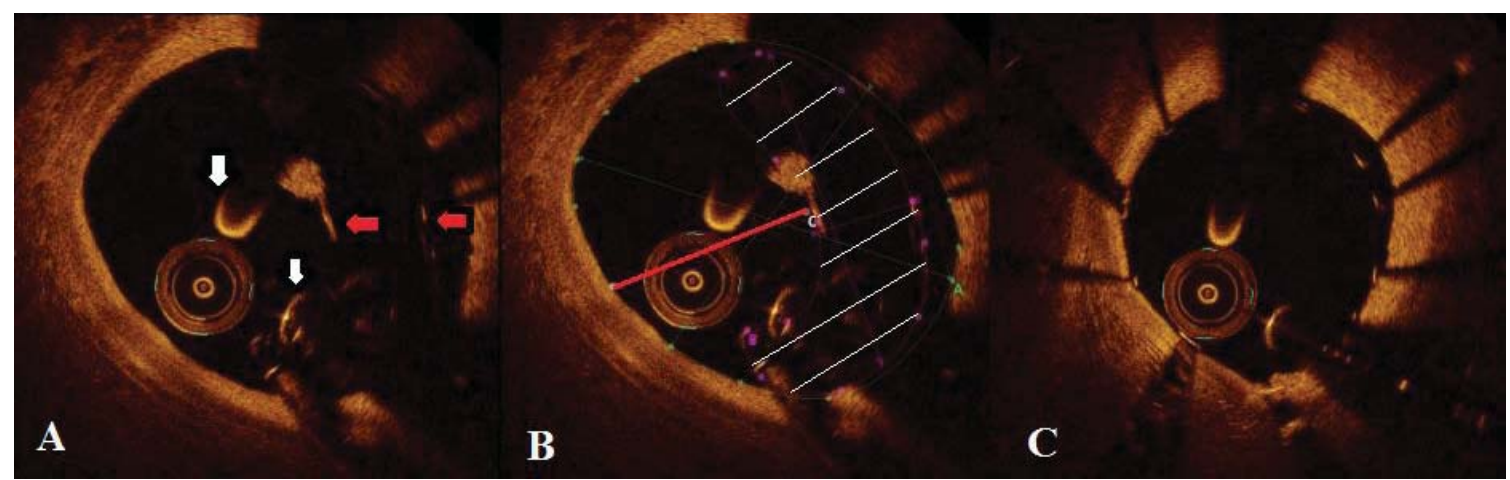

Figure 1: An Example of OCT evidence of extreme stent malapposition

(A) Wire exchange was done improperly and the wires (white arrows) entered the stent through a side cell instead of entering from the proximal inflow (red arrows). (B) Maximum malapposition distance $\left(1.9 \mathrm{~mm}\right.$ ) (red line) with stent underexpansion $(40.43 \%)$ and in-stent CSA $\left(3.74 \mathrm{~mm}^{2}\right)$, resulting in "extreme stent malapposition" (white arrows). (C) After passing through a side cell, the wires entered the stented distal segment and follow the proper course.

path inside the main and the side branch. Three dimensional OCT will have a great value in this clinical setting to ensure that guiding wires have already passed through the proper course within the proximal inflow of the stent.

Furthermore, post-dilatation with higher pressure and/ or bigger balloon size may be needed to decrease the degree of malapposition with subsequent avoidance of any further adverse cardiac events. However, larger future studies are required to prove these beneficial effect and long term outcomes.

\section{Study limitations}

The present study has some limitations. First, our analysis was performed in a limited sample of OCT cases. Thus, these conclusions should be drawn with caution and need to be confirmed by a larger study population, primarily to understand the clinical relevance of these OCT findings. Second, this study used a retrospective approach based on a registry database. Therefore, potential selection bias is unavoidable. However, data collection, data processing, and statistical analyses were conducted by independent research personnel, independent clinicians, and independent statisticians. Finally, the long term outcomes have to be further assessed in future larger studies.

\section{Conclusion}

The treatment of bifurcation lesions requiring a KBI technique can be complicated by an extreme degree of stent malapposition; or even stent crushing, despite achieving acceptable angiographic results. This may be attributed to the wrong passage of one or both guide-wires through the stents during the wire exchange.-Accordingly, OCT; especially three dimensional OCT, has a great value before doing KBI to ensure the correct passage of guidewires through both main vessel and side branch ostium, and to properly select the optimal cell for optimal stent dilatation.

\section{Supplementary data}

OCT image analysis $\mathrm{s}$ described in details in the online appendix.

\section{Ethical approval}

The study was approved by the Ethics Committee of our Institution.

\section{Informed consent}

Informed consent was obtained from all individual participants included in the study.

\section{References}

1. Sharma SK, Sweeny J, Kini AS (2010) Coronary bifurcation lesions: a current update. Cardiol Clin 28: 55-70. Link: https://bit.ly/33TzQGW

2. Hildick-Smith D, Lassen JF, Albiero R, Lefevre T, Darremont O, et al (2010) Consensus from the $5^{\text {th }}$ European Bifurcation Club meeting. Eurolntervention 6: 34-38. Link: https://bit.ly/2JDzvkZ

3. Prati F, Di Vito L, Biondi-Zoccai G, Occhipinti M, La Manna A, et al. (2012) Angiography alone versus angiography plus optical coherence tomography to guide decision-making during percutaneous coronary intervention: The Centro per la Lotta contro I'Infarto-Optimisation of Percutaneous Coronary Intervention (CLI-OPCI) study. Eurolntervention 8: 823-829. Link: https://bit.ly/36Y4EIA

4. Burzotta F, Talarico GP, Trani C, De Maria GL, Pirozzolo G, et al. (2014) Frequency-domain optical coherence tomography findings in patients with bifurcated lesions undergoing provisional stenting. Eur Heart $\mathrm{J}$ Cardiovasc Imaging 15: 547-555. Link: https://bit.ly/3gpdwKs

5. Imola F, Mallus MT, Ramazzotti V, Manzoli A, Pappalardo A, et al. (2010) Safety and feasibilty of frequency domain optical coherence tomography to guide decision making in percutaneous coronary intervention. Eurolntervention 6 : 575-581. Link: https://bit.ly/33YbrzY

6. Medina A, Suarez de Lezo J, Pan M (2006) A new classification of coronary bifurcation lesions. Rev Esp Cardiol 59: 183. Link: https://bit.ly/37LN9un

7. Louvard $Y$, Lefèvre $T$ (2011) Tools \& Techniques: $\mathrm{PCl}$ in coronary bifurcations lesions. Eurointervention 7: 160-163. Link: https://bit.ly/2L9ESZI

8. lakovou I, Foin N, Andreou A, Viceconte N, Di Mario C (2011) New strategies in the treatment of coronary bifurcations. Herz 36: 198-212. Link: https://bit.ly/3nOyEJw

9. Prati F, Regar E, Mintz GS, Arbustini E, Di Mario C, et al. (2010) Expert's OCT Review Document. Expert review document on methodology, terminology, and clinical applications of optical coherence tomography: physical principles, methodology of image acquisition, and clinical application for assessment 
of coronary arteries and atherosclerosis. Eur Heart J 31: 401-415. Link: https://bit.ly/2VWVy8w

10. Prati F, Guagliumi G, Mintz GS, Costa M, Regar E, et al. (2012) Expert review document part 2. Methodology, terminology and clinical applications of optical coherence tomography for the assessment of interventional procedures. Eur Heart J 33: 2513-2522. Link: https://bit.ly/3n0yW34

11. Tearney GJ, Regar E, Akasaka T, Adriaenssens T, Barlis P, et al. (2012) Consensus standards for acquistion, measurement, and reporting of intravascular optical coherence tomography studies: a report from the International Working Group for Intravascular Optical Cohenernce Tomography Standardization and Validation. J Am Coll Cardiol 59: 1058-1072. Link: https://bit.ly/39VIQzk

12. Di Vito L, Yoon JK, Kato K, Yonetsu T, Vergallo R, et al. (2014) Comprehensive overview of definitions for optical coherence tomography-based plaque and stent analyses. Coron Artery Dis 25: 172-185. Link: https://bit.ly/3gqKmut

13. Räber L, Mintz GS, Koskinas KC, Johnson TW, Holm NR, et al. (2018) Clinical use of intracoronary imaging. Part 1: guidance and optimization of coronary interventions. An expert consensus document of the European Association of Percutaneous Cardiovascular Interventions. Eurolntervention 14: 656-677.

14. Johnson TW, Räber L, Di Mario C, Bourantas C, Jia H, et al. (2019) Clinical use of intracoronary imaging. Part 2: acute coronary syndromes, ambiguous coronary angiography findings, and guiding interventional decision-making: an expert consensus document of the European Association of Percutaneous Cardiovascular Interventions. Eurolntervention 15: 44-51.

15. De Jaegere $P$, Mudra $H$, Figulla $H$, Almagor $Y$, Doucet $S$, et al. (1998) Intravascular ultrasound-guided optimized stent deployment. Immediate and
6 months clinical and angiographic results from the multicenter ultrasound stenting in coronaries study (music study). Eur Heart J 19: 1214-1223. Link: https://bit.ly/33QVb3V

16. Cook S, Wenaweser P, Togni M, Billinger M, Morger C, et al. (2007) Incomplete stent apposition and very late stent thrombosis after drug-eluting stent implantation. Circulation 115: 2426-2434. Link: https://bit.ly/2JDBrKh

17. Hong MK, Mintz GS, Lee CW, Park DW, Lee SW, et al. (2007) Impact of late drug-eluting stent malapposition on 3-year clinical events. J Am Coll Cardiol 50: 1515-1516. Link: https://bit.ly/3nOzNki

18. Ozaki Y, Okumura M, Ismail TF, Naruse H, Hattori K, et al. (2010) The fate of incomplete stent apposition with drug-eluting stents: an optical coherence tomography-based natural history study. Eur Heart J 31: 1470-1476. Link: https://bit.ly/3qHElyj

19. Otake H, Shite J, Ako J, Shinke T, Tanino Y, et al. (2009) Local determinants of thrombus formation following sirolimus-eluting stent implantation assessed by optical coherence tomography. JACC cardiovasc Interv 2: 459-466. Link: https://bit.ly/3n002aw

20. Im E, Kim BK, Ko YG, Shin DH, Kim JS, et al. (2014) Incidences, predictors, and clinical outcomes of acute and late stent malapposition detected by optical coherence tomography after drug-eluting stent implantation. Circ Cardiovasc Interv 7: 88-96. Link: https://bit.ly/36Wupc7

21. Prati F, Kodama T, Romagnoli E, Gatto L, Di Vito L, et al. (2015) Suboptimal stent deployment is associated with subacute stent thrombosis: optical coherence tomography insights from a multicenter matched study. From the CLI Foundation investigators: the CLI-THRO study. Am Heart J 169: 249-256. Link: https://bit.ly/3qCOqwh
Discover a bigger Impact and Visibility of your article publication with Peertechz Publications

Copyright: (c) 2020 Refaat $\mathrm{H}$. This is an open-access article distributed under the terms of the Creative Commons Attribution License, which permits unrestricted use, distribution, and reproduction in any medium, provided the original author and source are credited. 